\title{
Incidence of late vitamin $K$ deficiency bleeding in newborns in the Netherlands in 2005: evaluation of the current guideline
}

\author{
Marloes M. IJland • Rob Rodrigues Pereira • \\ Elisabeth A.M. Cornelissen
}

Received: 14 January 2007 / Accepted: 6 February 2007 / Published online: 1 March 2007

(C) Springer-Verlag 2007

\begin{abstract}
Vitamin K prophylaxis is recommended to prevent the hazard of haemorrhage caused by vitamin $\mathrm{K}$ deficiency in newborns. The present Dutch guideline recommends $1 \mathrm{mg}$ of vitamin $\mathrm{K}_{1}$ orally at birth, followed by a daily dose of $25 \mu \mathrm{g}$ of vitamin $\mathrm{K}_{1}$ from 1 to 13 weeks of age for breastfed infants. Since the introduction of this prophylaxis, the incidence of vitamin $\mathrm{K}$ deficiency bleeding (VKDB) has decreased; however, late VKDB is still reported. From 1 January to 31 December 2005, a nationwide active surveillance was performed by the Netherlands Paediatric Surveillance Unit (NSCK) to study the current incidence and aetiology of late VKDB in infants. Six cases could be validated as late VKDB: all were breastfed, one fatal idiopathic intracranial haemorrhage at the age of 5 weeks and five bleedings secondary to an underlying cholestatic liver disease between the age of 3 and 7 weeks. The total incidence of late VKDB and idiopathic late VKDB was calculated to be 3.2 (95\% CI: $1.2-6.9)$ and 0.5 (95\% CI: 0-2.9) per 100,000 live births, respectively. With the current Dutch guideline, idiopathic late VKDB is rare but late VKDB secondary to cholestasis still occurs in breastfed infants. Doubling the daily dose of vitamin $\mathrm{K}_{1}$ to $50 \mu \mathrm{g}$, as is comparable to formula-feeding, may possibly prevent VKDB in this group. Further research, however, is needed to prove this hypothesis.
\end{abstract}

M. M. IJland $(\bowtie) \cdot$ E. A. Cornelissen

Department of Paediatrics 833,

Radboud University Nijmegen Medical Centre,

P.O. Box 9101, 6500 HB, Nijmegen, The Netherlands

e-mail: m.ijland@cukz.umcn.nl

\section{R. R. Pereira}

Department of Paediatrics,

Netherlands Organisation for Applied Scientific Research (TNO),

P.O. Box 2215, 2301 CE, Leiden, The Netherlands
Keywords Vitamin K · Prophylaxis · Vitamin K deficiency · Newborn · Infant

$\begin{array}{ll}\text { Abbreviations } \\ \text { VKDB } & \text { vitamin K deficiency bleeding } \\ \text { HDN } & \text { haemorrhagic disease of the newborn } \\ \text { CI } & \text { confidence interval } \\ \text { PIVKA } & \text { protein induced by vitamin K absence } \\ \text { NSCK } & \text { Netherlands Paediatric Surveillance Unit }\end{array}$

\section{Introduction}

Vitamin K deficiency can cause severe haemorrhage in the newborn. The term "haemorrhagic disease of the newborn" (HDN) was coined by Charles Townsend in 1894 to describe an acquired bleeding disorder in the newborn due to vitamin $\mathrm{K}$ deficiency [26]. Nowadays, the term HDN is replaced by vitamin $\mathrm{K}$ deficiency bleeding (VKDB), as neonatal bleeding is often not due to vitamin $\mathrm{K}$ deficiency and VKDB often occurs after the 4-week neonatal period [23].

VKDB can be classified according to the time of presentation after birth into early $(0-24 \mathrm{~h})$, classical (17 days) and late (2-12 weeks) VKDB. Late VKDB occurs primarily in exclusively breastfed infants who have received no or inadequate vitamin $\mathrm{K}$ prophylaxis. In addition, intestinal malabsorption defects (cholestatic jaundice, cystic fibrosis, $\alpha-1$-antitrypsin deficiency etc.) are a well known frequent cause of late VKDB [13]. In some children, "warning bleeds" such as mild bruises, nose bleeds or umbilical oozing are the first manifestation of VKDB. In about $50 \%$ of the cases in late VKDB, intracranial haemorrhage occurs, accounting for death and serious neurological and mental handicaps [22]. The efficacy of 
neonatal vitamin $\mathrm{K}$ prophylaxis (oral or parenteral) in the prevention of classic VKDB is firmly established [16]. It has been the standard of care since the Committee on Nutrition of the American Academy of Paediatrics recommended to administer vitamin $\mathrm{K}$ prophylaxis to all newborn infants in 1961 [1]. Since then, many countries adopted this recommendation, although controversies concerning the best dose, route and frequency of administration still exist.

In 1990, the Dutch Paediatric Association recommended the administration of a single oral dose of $1 \mathrm{mg}$ of vitamin $\mathrm{K}_{1}$ at birth to all healthy infants. Parenteral administration of vitamin $\mathrm{K}_{1}$ at birth was recommended for newborns especially at risk (preterm babies, babies born with instrumental help or caesarean section, asphyxia or if maternal medication was interfering with coagulation). For infants who are largely or fully breastfed, a daily dose of $25 \mu \mathrm{g}$ of vitamin $\mathrm{K}_{1}$ orally was recommended from 1 to 13 weeks of age. In case of additional risk factors like a known malabsorption, this dose should be increased to $50 \mu \mathrm{g}$ per day [29].

After the introduction of this guideline, the incidence of late VKDB, which was studied by a nationwide active surveillance performed by the Netherlands Paediatric Surveillance Unit (NSCK) in 1992 to 1994, decreased from about 7.0 to $1.1 / 100,000$ live births [2]. However, still, some cases of late VKDB have been reported in the Netherlands, merely due to an underlying cholestatic liver disease $[7,10,11]$.

Therefore, a one-year surveillance was started again to study the current incidence and the aetiology of late VKDB in the Netherlands. Discussion will rise about the efficacy of the current guideline in order to completely prevent late VKDB.

\section{Methods}

From 1 January to 31 December 2005, an active surveillance programme for VKDB was in operation in the Netherlands, using methods developed by the British Paediatric Association Surveillance Unit [8]. Surveillance was based on monthly report cards sent to paediatricians responsible for in- and outpatient care in all hospitals by the NSCK. A "nothing to report" option was included. The return rate of these report cards was $94.7 \%$ in 2004 [17].

The paediatricians were asked to report all infants in whom bleeding may have resulted from VKDB. The reported cases were validated with a questionnaire asking for information about the infant, type of feeding, clinical presentation, dose of vitamin K prophylaxis, route of vitamin $\mathrm{K}$ prophylaxis, associated diseases and laboratory data. For all reported cases, we asked for an anonymous hospital discharge letter to verify the diagnosis of late-onset VKDB.
The case definition of late-onset VKDB was as internationally defined: any infant between 8 days to 26 weeks of age, with spontaneous bruising, bleeding or intracranial haemorrhage associated with a grossly prolonged prothrombin assay, not due to an inherited coagulopathy or disseminated intravascular coagulation [23].

Confirmed VKDB was diagnosed when the prothrombin assay results were grossly abnormal compared with the standards for age: international normalized ratio (INR) $\geq 4$ control value, prothrombin time (PT) $\geq 4$ control value and at least one of the following was present:

1. Platelet count normal or raised and normal fibrinogen

2. Prothrombin assay returned to normal after vitamin $\mathrm{K}$ administration

3. Concentration of proteins induced by vitamin $\mathrm{K}$ absence (PIVKA) exceeded normal controls

PIVKA is a sensitive indicator of vitamin $\mathrm{K}$ status, allowing the detection of subclinical deficiency states which would not be detected by conventional coagulation assays [20].

Idiopathic cases were defined as cases in whom no factor predisposing to vitamin $\mathrm{K}$ deficiency was identified. Secondary cases were those in whom an underlying condition such as cholestasis or other causes of malabsorption of vitamin $\mathrm{K}$ could be identified.

Vitamin K prophylaxis was considered to be "as recommended" if the Dutch guideline was followed at the time of bleeding: $1 \mathrm{mg}$ of vitamin $\mathrm{K}_{1}$ (oral, intravenous, intramuscular) directly after birth, followed by a daily dose of $25 \mu \mathrm{g}$ of vitamin $\mathrm{K}_{1}$ from 1 to 13 weeks of age for all breastfed babies.

The Konakion mixed micellar preparate (Phytomenadion $10 \mathrm{mg} / \mathrm{ml}$, Hoffmann-La Roche, Basel, Switzerland), which can be used for both oral, intramuscular and intravenous administration, an oral preparate called Davitamon $\mathrm{K}$ (marketed by Chefaro, Rotterdam, the Netherlands, $25 \mu \mathrm{g} /$ $5 \mathrm{gtt})$ and an oral preparate, Phytomenadion, which is made by the Dutch pharmacist Mixtura (Phytomenadion 10 $\mathrm{mg} / \mathrm{ml}$ FNA) were the only vitamin K preparations licensed in the Netherlands.

The $95 \%$ confidence intervals (CI) were calculated according to a binomial distribution and the chi-squared test was used for the comparison of incidences between different periods, with a value of $P<0.05$ being considered as significant.

\section{Results}

The response rate to the surveillance amounted to $93.4 \%$ and the response to our questionnaires was $100 \%$. In total, seven cases of late VKDB were reported: four reports from 
academic paediatric centres and three from general district hospitals. A hospital discharge letter was obtained in six cases. In all cases, the diagnosis could be verified by the completed questionnaire or the additional discharge letter.

One case did not fulfil the criteria of the case definition because there were no clinical signs of bleeding, only biochemical clotting disorders due to a vitamin $\mathrm{K}$ deficiency.

Six cases fulfilled the criteria of the case definition and could be validated as late VKDB. The surveillance data are shown in Table 1. The mean age of presentation was 5 weeks and 2 days, and all of the cases were exclusively breastfed. In all cases, the PT time or INR was at least four times greater than normal and vitamin $\mathrm{K}$ deficiency was confirmed by a documented PT or INR normalisation after the administration of vitamin K. Five of the cases also received fresh frozen plasma.

Concerning the cause of VKDB, there was one case of idiopathic VKDB, who presented with signs of bleeding at the age of 5 weeks. She was breastfed and died due to the consequence of an intracranial bleeding. She received exactly the recommended prophylaxis. Unfortunately, no post-mortem obduction was performed but, biochemically, there were no signs of cholestasis. Five out of six cases could be validated as secondary late VKDB. The age of presentation in this group was between 3 and 7 weeks of age. All of these bleedings were due to an underlying cholestasis which was diagnosed after the first presentation of bleeding. In two cases, an intracranial bleeding was the first presenting sign. Four cases were diagnosed as having a bile duct atresia. All infants had been exclusively breastfed and all had received exactly the recommended prophylaxis.

In the study period, the number of live births amounted to 187,910 [21]. Therefore, the total incidence of late VKDB and idiopathic late VKDB was calculated to be 3.2 (95\% CI: $1.2-6.9)$ and 0.5 (95\% CI: $0-2.9)$ per 100,000 live births, respectively.

\section{Discussion}

Data from the United Kingdom, Germany and Switzerland prove that intramuscular vitamin $\mathrm{K}_{1}$ prophylaxis $(1 \mathrm{mg})$ is highly effective in the prevention of late VKDB. This is supported by data from Australia, which demonstrate a higher incidence of late VKDB in babies who received oral vitamin $\mathrm{K}$ compared to those with parenteral vitamin $\mathrm{K}$ at birth. However, most of these failures of oral vitamin $\mathrm{K}$ were in cases reported with an underlying cholestatic liver disease [3, 12, 14, 25, 32, 33].

In 1992, Golding et al. [5] reported an increased risk of developing childhood cancer after parenteral vitamin $\mathrm{K}_{1}$ prophylaxis. Recent studies, however, show that solid tumours are no commoner in children who had parenteral vitamin K. Although no convincing evidence between parenteral vitamin $\mathrm{K}$ and childhood leukaemia was found in these studies, it cannot be fully excluded that there is no risk $[4,18]$.

Since the report of Golding et al., there has been an increasing trend towards oral vitamin $\mathrm{K}$ administration and many oral prophylaxis regimes have been developed.

In 1997, we summarised the results of surveillance studies of over 2 million infants in four different countries using different multiple oral dose schedules and parenteral administration of vitamin $\mathrm{K}$. A daily low oral dose of $25 \mu \mathrm{g}$ of vitamin $K_{1}$ following an initial oral dose of $1 \mathrm{mg}$ vitamin $\mathrm{K}_{1}$ directly after birth for exclusively breastfed infants, as was used in the Netherlands since 1990, seemed to be as effective as parenteral vitamin $\mathrm{K}_{1}$ prophylaxis [3].

The present surveillance study shows that the current Dutch guideline still seems quite effective in preventing idiopathic late VKDB, but it is insufficient against secondary late VKDB. In our surveillance, the incidence of all late VKDB and idiopathic late VKDB was $3.2(95 \%$ CI: $1.2-6.9)$ and 0.5 (95\% CI: 0-2.9) per 100,000 live

Table 1 Confirmed cases of late vitamin K deficiency bleeding (VKDB) in the Netherlands from 1 January to 31 December 2005

\begin{tabular}{|c|c|c|c|c|c|c|}
\hline $\begin{array}{l}\text { Patient; sex; } \\
\text { age (weeks) }\end{array}$ & Presentation & Feeding & Vitamin K prophylaxis & $\begin{array}{l}\text { Prothrombin assay } \\
\text { (after vitamin } \mathrm{K} \text { administration) }\end{array}$ & $\begin{array}{l}\text { Additional } \\
\text { morbidity }\end{array}$ & $\begin{array}{l}\text { Outcome } \\
\text { of bleeding }\end{array}$ \\
\hline $\begin{array}{l}\text { A; female; } \\
5+1 / 7\end{array}$ & $\begin{array}{c}\text { Intracranial } \\
\text { bleeding }\end{array}$ & Breastfeeding & $\begin{array}{l}\text { Birth: } 1 \mathrm{mg} \\
\text { p.o. } \rightarrow 25 \mu \mathrm{g} / \text { day }\end{array}$ & $\begin{array}{l}\mathrm{PT}>120 \mathrm{~s}(13.3) \\
\quad \text { APTT }>120 \mathrm{~s}(37)\end{array}$ & No & Died \\
\hline $\begin{array}{l}\mathrm{B} \text {; female; } \\
\quad 6+6 / 7\end{array}$ & $\begin{array}{c}\text { Intracranial } \\
\text { bleeding }\end{array}$ & Breastfeeding & $\begin{array}{l}\text { Birth: } 1 \mathrm{mg} \\
\text { p.o. } \rightarrow 25 \mu \mathrm{g} / \text { day }\end{array}$ & $\begin{array}{l}\text { INR }>8 \quad(\text { INR }<2) \\
\text { APTT }>240 \text { s }(49)\end{array}$ & $\begin{array}{l}\text { Biliary } \\
\text { atresia }\end{array}$ & $\begin{array}{l}\text { Hemipareses } \\
\text { right }\end{array}$ \\
\hline $\begin{array}{r}\text { C; male; } \\
4+4 / 7\end{array}$ & $\begin{array}{l}\text { Intracranial } \\
\text { bleeding }\end{array}$ & Breastfeeding & $\begin{array}{l}\text { Birth: } 1 \mathrm{mg} \\
\text { p.o. } \rightarrow 25 \mu \mathrm{g} / \text { day }\end{array}$ & $\begin{array}{l}\text { PT }>90 \text { s }(30) \\
\text { APTT }>120 \text { s }(38) ; \\
\text { Vitamin K: } 0.1 \mathrm{nmol} / 1\end{array}$ & $\begin{array}{l}\text { Biliary } \\
\text { atresia }\end{array}$ & $\begin{array}{l}\text { Hemipareses } \\
\text { right }\end{array}$ \\
\hline $\begin{array}{r}\mathrm{D} ; \text { male; } \\
5+2 / 7\end{array}$ & $\begin{array}{l}\text { Nasal } \\
\text { bleeding }\end{array}$ & Breastfeeding & $\begin{array}{l}\text { Birth: } 1 \mathrm{mg} \\
\text { p.o. } \rightarrow 25 \mu \mathrm{g} / \text { day }\end{array}$ & $\begin{array}{l}\text { PT>75 s (normal); } \\
\text { APTT: } 118 \mathrm{~s} \text { (normal) }\end{array}$ & $\begin{array}{l}\text { Biliary } \\
\text { atresia }\end{array}$ & No sequelae \\
\hline $\begin{array}{r}\text { E; male; } \\
6+2 / 7\end{array}$ & $\begin{array}{l}\text { Nasal } \\
\text { bleeding }\end{array}$ & Breastfeeding & $\begin{array}{l}\text { Birth: } 1 \mathrm{mg} \\
\text { p.o. } \rightarrow 25 \mu \mathrm{g} / \text { day }\end{array}$ & $\begin{array}{l}\mathrm{PT}>165 \mathrm{~s} \text { (normal); } \\
\quad \text { APTT }>240 \text { s (normal) }\end{array}$ & $\begin{array}{l}\text { Biliary } \\
\text { atresia }\end{array}$ & No sequelae \\
\hline $\begin{array}{r}\text { F; male; } \\
3+6 / 7\end{array}$ & $\begin{array}{l}\text { Nasal } \\
\text { bleeding }\end{array}$ & Breastfeeding & $\begin{array}{l}\text { Birth: } 1 \mathrm{mg} \\
\text { p.o. } \rightarrow 25 \mu \mathrm{g} / \text { day }\end{array}$ & $\begin{array}{l}\text { PT>71 s }(12.7) \\
\text { APTT: } 128 \text { s }(39.1)\end{array}$ & Cholestasis & No sequelae \\
\hline
\end{tabular}


births, respectively. The incidence of the latter is comparable to $0.5(95 \%$ CI: $0.1-1.6)$ per 100,000 live births reported in our surveillance study performed by the same Netherlands Paediatric Surveillance Unit (NSCK) in 19921994 [2]. The incidence of late VKDB secondary to an underlying cholestatic liver disease is, however, significantly higher $(P<0.05) ; 2.7$ (95\% CI: 0.9-6.2) compared to 0.7 (95\% CI: $0.1-2.0)$ in 1992-1994. A higher incidence of cholestatic liver diseases in general or a delayed recognition of symptoms can be explanations for this difference. Unfortunately, data about the incidence or recognition of cholestatic liver diseases in the Netherlands are not available.

In this surveillance, there were no reports of late VKDB after parenteral administration of vitamin $\mathrm{K}_{1}$. This can be explained by the assumption of the higher efficacy of parenteral vitamin $\mathrm{K}_{1}$ or the low use of intramuscular and intravenous vitamin $\mathrm{K}_{1}$ these days.

Since 1994, a new preparate, Konakion mixed micellar, has been available. This mixed micellar formulation is prepared with the phospholipids lecithin and the bile salt glycocholic acid, and it was presumed that this preparate would reduce the incidence of late VKDB due to a better absorption of oral vitamin K. However, a recent randomised controlled trial shows that the mixed micellar vitamin $\mathrm{K}$ gives unreliable and still severely impaired intestinal absorption in infants with cholestasis [15]. Furthermore, von Kries et al. [31] reported no significant reduction in the incidence of late VKDB in healthy infants and infants with an underlying cholestatic liver disease with this preparate compared to the use of the original Konakion (Cremophor EL) and Kanavit (Polysorbat 80).

In view of the fact that vitamin $\mathrm{K}$ has limited tissue reserves and is rapidly catabolised, with $60-70 \%$ of a single dose being excreted via the urine and bile in about 3 days, it seems reasonable that repeated doses rather than a higher single dose is more effective in preventing late VKDB [15].

An important study from Denmark has established that $1 \mathrm{mg}$ of oral vitamin $\mathrm{K}_{1}$ given weekly during the first 3 months of life, following an initial oral dose of $2 \mathrm{mg}$ of vitamin $K_{1}$ directly after birth, is as effective as $1 \mathrm{mg}$ of vitamin $\mathrm{K}_{1}$ given intramuscularly at birth [9]. Therefore, we hypothesise that the dosage of $25 \mu \mathrm{g}$ of vitamin $\mathrm{K}_{1}$ daily is not enough to prevent the secondary cases of late VKDB, as we encountered in this study.

In most co-operative studies, the upper age limit for inclusion was set arbitrarily at the end of 12 weeks of age [32]. In our study, we included infants presenting with VKDB up to the age of 26 weeks of age, as suggested by Tripp et al. [27]. However, no infant between 12 and 26 weeks of age was reported.

The mean age of all infants with late VKDB was 5 weeks, which is comparable to other reports [22].
In our study, the boy:girl ratio was 2.5:1. Why late VKDB occurs more in boys than girls is unknown, but this is consistent with other European reports [22, 24].

Unfortunately, this study has some limitations. First, this surveillance was based on one data source only: the Netherlands Paediatric Surveillance Unit. In spite of the high return rate of the report cards $(93.4 \%)$ ), it is plausible that dramatic conditions, such as intracranial bleedings, are more likely to be reported, as also noted by von Kries et al. [31]. For this reason, our data could give an under-reporting of the true incidence of late VKDB in the Netherlands. However, the fact that $50 \%$ of late VKDB cases were intracranial bleedings is comparable to other, larger reports $[3,13,14,19,22,30,31,33]$.

Secondly, the surveillance lasted only 1 year. In all probability, the confidence interval would be smaller when the length of the surveillance was prolonged. Third, the proportion of infants that is breastfed is unknown, and, additionally, we lack data about compliance to the prophylaxis. It is likely, however, that less than $100 \%$ of the eligible cases received the recommended prophylaxis. Prophylaxis failure, therefore, is likely to be underestimated due to a greater denominator than the true numbers exposed.

We would suggest to double the daily dose of vitamin $\mathrm{K}_{1}$ to $50 \mu \mathrm{g}$ for all breastfed babies from 1 to 13 weeks of age to prevent bleedings in infants with an underlying cholestatic liver disease as well. This amount is comparable to the ingested dose of vitamin $\mathrm{K}_{1}$ by formula-feeding [6]. Formula is supplemented with vitamin $\mathrm{K}_{1}$ to a minimal concentration of $50 \mu \mathrm{g} / \mathrm{l}$. VKDB are not reported in formula-fed babies and there is no evidence that they are at an increased risk of childhood cancer [28]. Studies with such a concentration of vitamin $\mathrm{K}_{1}$ have never been performed and further research is necessary to study the efficacy of this prophylaxis in infants with underlying cholestatic liver disease. Due to the low incidence of late VKDB, it would be difficult to perform a randomised trial of $25 \mu \mathrm{g}$ versus $50 \mu \mathrm{g}$ of vitamin $\mathrm{K}_{1}$ daily. Alternatively, a new surveillance for 1 or 2 years after implementing $50 \mu \mathrm{g}$ of vitamin $\mathrm{K}_{1}$ as the prophylaxis could give an indication of the efficacy of this dose.

Furthermore, an earlier recognition of symptoms associated with cholestatic liver disease and immediate investigation and treatment of "warning bleeds" helps to prevent the severe consequences of secondary late VKDB.

In conclusion, with the current guideline of vitamin $\mathrm{K}$ prophylaxis in the Netherlands, idiopathic late VKDB is rare, but late VKDB secondary to an underlying cholestatic liver disease still occurs. We suggest to double the daily maintenance dose of vitamin $\mathrm{K}_{1}$ to $50 \mu \mathrm{g}$ per day for all breastfed infants from 1 to 13 weeks of age in order to prevent bleedings in children with an underlying cholestatic liver disease as well. Further research, however, is recommended. 
Acknowledgement This work would not have been possible without help from the Netherlands Paediatric Surveillance Unit (NSCK).

\section{References}

1. American Academy of Pediatrics, Committee on Nutrition (1961) Vitamin K compounds and the water-soluble analogues: use in therapy and prophylaxis in pediatrics. Pediatrics 28:501-507

2. Cornelissen EAM, Hirasing RA, Monnens LA (1996) Prevalence of hemorrhages due to vitamin $\mathrm{K}$ deficiency bleeding in the Netherlands, 1992-1994 (in Dutch). Ned Tijdschr Geneeskd 140 (17):935-937

3. Cornelissen M, von Kries R, Loughnan P, Schubiger G (1997) Prevention of vitamin $\mathrm{K}$ deficiency bleeding: efficacy of different multiple oral dose schedules of vitamin K. Eur J Pediatr 156 (2): $126-130$

4. Fear NT, Roman E, Ansell P, Simpson J, Day N, Eden OB; United Kingdom Childhood Cancer Study (2003) Vitamin K and childhood cancer: a report from the United Kingdom Childhood Cancer Study. Br J Cancer 89(7):1228-1231

5. Golding J, Greenwood R, Birmingham K, Mott M (1992) Childhood cancer, intramuscular vitamin $\mathrm{K}$, and pethidine given during labour. BMJ 305(6849):341-346

6. Greer FR, Marschall S, Cherry J, Suttie JW (1991) Vitamin K status of lactating mothers, human milk, and breast-feeding infants. Pediatrics 88(4):751-756

7. Hack WWM, van der Blij JF, Tegelaers FPW, Peters M (1996) An infant with a fatal cerebral hemorrhage due to vitamin $\mathrm{K}$ deficiency (in Dutch). Ned Tijdschr Geneeskd 140(17):937-939

8. Hall SM, Glickman M (1998) The British Paediatric Surveillance Unit. Arch Dis Child 63(3):344-346

9. Hansen KN, Minousis M, Ebbesen F (2003) Weekly oral vitamin K prophylaxis in Denmark. Acta Paediatr 92(7):802-805

10. van Hasselt PM, Houwen RHJ, van Dijk ATH, Koning de TJ (2003) Vitamin K deficiency bleeding in an infant despite adequate prophylaxis (in Dutch). Ned Tijdschr Geneesk 147 (16):737-740

11. IJland MM, Cornelissen EAM, Steiner K (2004) An infant with a fatal cerebral bleeding due to vitamin K deficiency: do we have to change the current Dutch guideline? Tijdschr Kindergeneeskd $72: 138-141$

12. Lane PA, Hathaway WME (1985) Vitamin K in infancy. J Pediatr 106(3):351-359

13. Loughnan PM, McDougall PN (1993) Epidemiology of late onset haemorrhagic disease: a pooled data analysis. J Paediatr Child Health 29(3):177-181

14. McNinch AW, Tripp JH (1991) Haemorrhagic disease of the newborn in the British isles: two year prospective study. BMJ 303 (6810):1105-1109

15. Pereira SP, Shearer MJ, Williams R, Mieli-Vergani G (2003) Intestinal absorption of mixed micellar phylloquinone (vitamin $\mathrm{K}_{1}$ ) is unreliable in infants with conjugated hyperbilirubinaemia: implications for oral prophylaxis of vitamin $\mathrm{K}$ deficiency bleeding. Arch Dis Child Fetal Neonatal Ed 88(2):F113-F118
16. Puckett RM, Offringa M (2000) Prophylactic vitamin K for vitamin $\mathrm{K}$ deficiency bleeding in neonates. Cochrane Database of Systematic Reviews, Issue 4. Art. No.: CD002776. DOI 10.1002/ 14651858.CD002776

17. Rodrigues Pereira R, Rijpstra A (2005) Annual report, Netherlands Paediatric Surveillance Unit (NSCK), pp 7-13

18. Roman E, Fear NT, Ansell P, Bull D, Draper G, McKinney P, Michaelis J, Passmore SJ, von Kries R (2002) Vitamin K and childhood cancer: analysis of individual patient data from six case-control studies. Br J Cancer 86(1):63-69

19. Schubiger G, Berger TM, Weber R, Bänziger O, Laubscher B; Swiss Paediatric Surveillance Unit (2003) Prevention of vitamin K deficiency bleeding with oral mixed micellar phylloquinone: results of a 6-year surveillance in Switzerland. Eur J Pediatr 162 (12):885-888

20. Shearer MJ (1995) Vitamin K. Lancet 345(8944):229-234

21. Statistics Netherlands, Voorburg/Heerlen, 2006. Available online at http://statline.cbs.nl/StatWeb/table.asp?PA=37296ned\&D1=57$67 \& \mathrm{D} 2=55 \& \mathrm{DM}=\mathrm{SLNL} \& \mathrm{LA}=\mathrm{n} 1 \& \mathrm{TT}=2$

22. Sutor AH, Dagres N, Niederhoff H (1995) Late form of vitamin K deficiency bleeding in Germany. Klin Pädiatr 207(3):89-97

23. Sutor AH, von Kries R, Cornelissen EAM, McNinch AW, Andrew M (1999) Vitamin K deficiency bleeding (VKDB) in infancy. ISTH Pediatric/Perinatal Subcommittee. International Society on Thrombosis and Haemostasis. Tromb Haemost 81 (3):456-461

24. Sutor AH, Scharbau O (1991) Effect of vitamin K prophylaxis on the incidence of late form of vitamin $\mathrm{K}$ deficiency bleeding. In: Suzuki S, Hathaway WE, Bonnar J, Sutor AH (eds) Perinatal thrombosis and haemostasis, Springer, New York

25. Tönz O, Schubiger G (1988) Neonatale vitamin-K-prophylaxe und vitamin-K-mangelblutungen in der Schweiz 1986-1988. Schweiz Med Wschr 118(47):1747-1752

26. Townsend CW (1894) The haemorrhagic disease of the newborn. Arch Paediatr 11:559-565

27. Tripp JH, Cornelissen EAM, Loughnan P, McNinch A, Schubiger G, von Kries R (1995) Suggested protocol for the reporting of prospective studies of vitamin $\mathrm{K}$ deficiency bleeding. In: Sutor AH, Hathaway WE (eds) Vitamin K in infancy. Schattauer, Stuttgart, Germany, pp 395-399

28. Tripp JH, McNinch AW (1998) The vitamin K debacle: cut the Gordian knot but first do no harm. Arch Dis Child 79(4):295297

29. Uitenhuis J (1990). Recommendations for vitamin K prophylaxis in infants. Ned Tijdschr Geneeskd 134:1642-1646

30. von Kries R, Hachmeister A, Göbel U (1999) Can 3 oral 2 mg doses of vitamin $\mathrm{K}$ effectively prevent late vitamin $\mathrm{K}$ deficiency bleeding? Eur J Pediatr 158(Suppl 3):S183-186

31. von Kries R, Hachmeister A, Göbel U (2003) Oral mixed micellar vitamin $\mathrm{K}$ for prevention of late Vitamin $\mathrm{K}$ deficiency bleeding. Arch Dis Child Fetal Neonatal Ed 88(2):F109-F112

32. von Kries R, Hanawa Y (1993) Neonatal vitamin K prophylaxis. Report of Scientific and Standardization Subcommittee on Perinatal Haemostasis. Thromb Haemost 69(3):293-295

33. Wariyar U, Hilton S, Pagan J, Tin W, Hey E (2000) Six years' experience of prophylactic oral vitamin K. Arch Dis Child Fetal Neonatal Ed 82(1):F64-F68 